\title{
Pattern of Pediatric trauma during covid-19 pandemic lockdown in Multan.
}

\begin{abstract}
Mahreen Zahra1, Muhammad Kashif ${ }^{2}$, Ikramullah Khan ${ }^{3}$, Mateullah Majid ${ }^{4}$
1. MBBS, FCPS (Pediatric Surgery) Assistant Professor Pediatric Surgery Children Hospital Multan.

2. MBBS, FCPS (Pediatric Surgery) Professor Pediatric Surgery Children Hospital Multan

3. MBBS, FCPS (General Surgery) Assistant Professor Pediatric Surgery Children Hospital Multan.

4. MBBS, FCPS (Pediatric Surgery)

Assistant Professor Pediatric Surgery Nishtar Hospital, Multan.

Correspondence Address:

Dr. Mahreen Zahra Khan

Department of Pediatric Surgery

Children Hospital and

Institute of Child Health Multan

mahreenzahra@live.com

Article received on:

ABSTRACT... Objectives: To determine the pattern of pediatric trauma during COVID-19 pandemic lockdown in Multan. Study Design: Cross-sectional study. Setting: Departments of Pediatric Emergency Two Major Hospitals of Multan. Period: 15 $15^{\text {th }}$ March 2020 till $30^{\text {th }}$ April 2020. Material \& Methods: A total of 231 patients were included in the study. Data on age, sex, mechanism and pattern of injury, severity of injury, body area involved and rural/urban housing was collected on a predesigned performa. Descriptive statistics were run using SPSS version 20. Results: Out of 231 patients, $168(72.7 \%)$ were male with the mean age of 6.01 years \pm 3.02 . Most of the injuries noted were fall $(64.9 \%)$ followed by burn $(12.98 \%)$, hit by some heavy object $(11.72 \%)$ and stab $(7.8 \%)$. Road side accidents were the least $(2.6 \%)$ common. There was no report of sexual abuse in children during this pandemic lockdown in Multan. Life threatening injuries were reported in $8.66 \%$ and $90 \%$ of the injuries were non-life or limb threatening. Regarding body area involved, head injuries remained the most common (37.23\%) followed by limb injuries (35.50\%) and the abdomen was the least common body area involved. Conclusion: It is concluded that during pandemic lock down most of the pediatric trauma is not severe and is still avoidable by increase public awareness programs regarding home safety and resource allocation.
\end{abstract}

13/05/2020

Accepted for publication:

$17 / 08 / 2020$

Key words: $\quad$ Pediatric Trauma, Covid-19, Pandemic Lockdown.

Article Citation: Zahra M, Kashif M, Khan I, Majid M. Pattern of Pediatric trauma during covid-19 pandemic lockdown in Multan. Professional Med J 2020; 27(12):2708-2712. https://doi.org/10.29309/TPMJ/2020.27.12.4795

\section{INTRODUCTION}

Traumatic injuries are a major cause of impairment or death in children ${ }^{1}$ but staying at home changes the pattern of these traumatic injuries affected by the presence of siblings and parents to keep a watch on them and exposure to the households for more than the usual free time. These injuries occur in various places during various activities and change in their patterns over time. ${ }^{2}$

Pediatric injuries have not been very well documented in medical literature in the perspective of holiday-related trauma. Earlier studies are done in the setup of festive holidays which does not reflect the circumstances that the whole world is facing at the moment of covid-19 pandemic lockdown. During covid-19 with special circumstances of forced stay at home, social distancing, fear of getting the disease and enthusiastic cleaning practices, the trends in trauma are changed.
Covid-19 crisis has caused negative impact on the psychosocial health of children. A report by Human Rights Watch dated April 9, 2020 shows that more than 1.5 billion students are out of school. ${ }^{3}$ According to world Economic Forum, the coronavirus pandemic and the unprecedented measures to contain its spread are disrupting nearly every aspect of children's lives: their health, development, learning, behavior, their families' economic security and their protection from violence and abuse and their mental health. ${ }^{4}$

According to previous literature, holidays have been consistently linked to an increased rate of trauma. ${ }^{5}$ Although Holiday related injuries are not studied and thus not well documented in the medical literature. ${ }^{6} \mathrm{~A} 13$ year retrospective cohort analysis done in New York showed most of the injuries were due to foreign body ingestion and glass injuries followed by burn. ${ }^{6}$ 
A Saudi Arabian study concluded no changes in the pattern of pediatric trauma Ramadan with an average of 1.6 day and non-Ramadan days of 1.7 per day. ${ }^{7}$ No similar studies in the background of holidays or covid-19 lockdown has been done in our region.

The aim of this study is to determine pattern of pediatric trauma during pandemic lockdown due to covid-19 in Multan and to identify the mechanism of injuries and their severity in order to lay down the strategies for social education of parents.

\section{MATERIAL \& METHODS}

This is a cross-sectional study done from $15^{\text {th }}$ March 2020 to $15^{\text {th }}$ April 2020 during pandemic lockdown in the pediatric emergency departments of Children Hospital and Institute of Child health Multan and Nishtar University Hospital Multan.

A total of 231 patients between the ages of 1 month-12 years of ages of both genders visiting pediatric surgical emergency were selected by non-probability consecutive sampling. Patients were triaged into three categories of non-life nonlimb threatening injuries, limb threatening injuries and life threatening injuries. Patients requiring admission were admitted and treated accordingly while others were managed as day care cases. All the data was collected directly from the parents/ guardians on a predesigned performa after taking their written informed consent. Data was abstracted as detailed history in terms of age, sex, domestic condition urban/rural and education of the parents, mechanism of injury and findings on physical examination. All the collected data was analyzed on SPSS version20.

Approval from the Ethical review boards was taken before the commencement of the study and consent of parents was also obtained.

\section{RESULTS}

Out of 231 patients were included in the study, males children were 168 (72.7\%) while female were $63(27.3 \%)$ with the mean age being 6.01 years \pm 3.02 . Demographic characteristics of the population is shown in Table-I.

There are two peaks of ages inflicted by trauma in both sexes, first peak is between $1 \mathrm{~m}$-2years and the other peak is between 4-10 years. Mean time of arrival in the emergency is $12.45 \mathrm{pm}$.

Most of the patients presented with history of fall $(64.9 \%)$ followed by burn $(12.98 \%)$ with only one $(0.43 \%)$ patient presented with low voltage electric burn, hit by some heavy object (11.72\%) and stab with knife $(7.8 \%)$ with one case $(0.43 \%)$ during fight. Road side accidents were the least common $(2.6 \%)$ to be reported. Not a single report of sexual abuse in children during this pandemic lockdown was reported in Multan which is a significant finding. Most of the injuries were non-life or limb threatening $(90 \%)$. While the life threatening injuries were mostly due to head injury and blunt abdominal trauma.

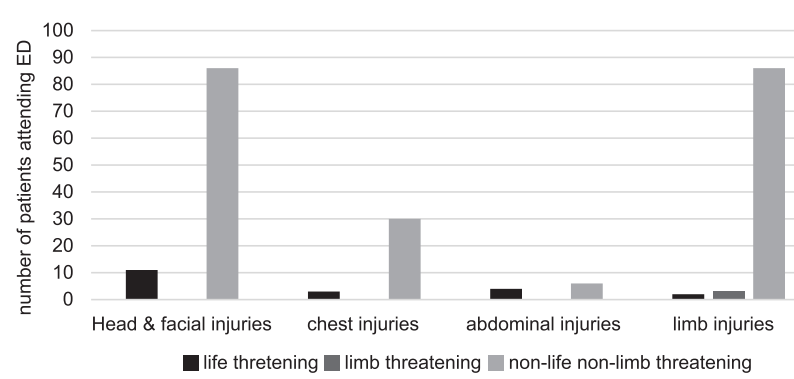

Figure-1. Severity of injuries with body area involved

\begin{tabular}{|c|c|c|c|}
\hline Type of Injury & $\begin{array}{l}\text { Life Threatening } \\
n=20(8.66 \%)\end{array}$ & $\begin{array}{l}\text { Limb Threatening } \\
\qquad n=3(1.33 \%)\end{array}$ & $\begin{array}{l}\text { Non-life, non-limb Threatening } \\
\qquad n=208(90.04 \%)\end{array}$ \\
\hline Fall & 16 (6.92\%) & $1(0.43 \%)$ & $133(57.58 \%)$ \\
\hline Hit by object & $2(0.86 \%)$ & $1(0.43 \%)$ & $24(10.39 \%)$ \\
\hline Stab & $0(0 \%)$ & $0(0 \%)$ & $18(7.8 \%)$ \\
\hline
\end{tabular}

Table-I. Age and sex distribution of children with trauma 


\begin{tabular}{|c|c|c|c|c|}
\hline \multirow{2}{*}{ No. } & \multirow{2}{*}{ Age (n=231) } & Male $(\mathbf{n = 1 6 8 )}$ & Female(n=63) & \multirow{2}{*}{$\begin{array}{c}\text { Total } \\
\mathbf{n}=\mathbf{2 3 1}\end{array}$} \\
\hline 1 & $1 \mathrm{~m}-2$ & $22(9.52 \%)$ & $18(7.8 \%)$ & $40(17.32 \%)$ \\
\hline 2 & $>2-4$ & $14(6.06 \%)$ & $4(1.73 \%)$ & $18(7.79 \%)$ \\
\hline 3 & $>4-6$ & $41(17.74 \%)$ & $15(6.5 \%)$ & $56(24.24 \%)$ \\
\hline 4 & $>6-8$ & $30(12.99 \%)$ & $17(7.36 \%)$ & $47(20.35 \%)$ \\
\hline 5 & $>8-10$ & $44(19.04 \%)$ & $11(4.76 \%)$ & $55(23.81 \%)$ \\
\hline 6 & $>10-12$ & $17(7.36 \%)$ & $3(1.3 \%)$ & $20(8.66 \%)$ \\
\hline
\end{tabular}

Table-II. Types of injury according to severity

\begin{tabular}{|l|c|c|c|c|c|}
\hline Age(in Years) & $\begin{array}{c}\text { Fall } \\
\mathbf{n = 1 5 0}\end{array}$ & $\begin{array}{c}\text { Burn } \\
\mathbf{n = 3 0}\end{array}$ & $\begin{array}{c}\text { Hit by Object } \\
\mathbf{n = 2 7}\end{array}$ & $\begin{array}{c}\text { Stab } \\
\mathbf{n = 1 8}\end{array}$ & $\begin{array}{c}\text { Road Side Accident } \\
\mathbf{n = 5}\end{array}$ \\
\hline $1 \mathrm{mo}-2$ & $31(13.4 \%)$ & $7(3.03 \%)$ & $2(0.86 \%)$ & 0 & 0 \\
\hline$>2-4$ & $10(4.33 \%)$ & $7(3.03 \%)$ & 0 & 0 & $1(0.43 \%)$ \\
\hline$>4-6$ & $39(16.88 \%)$ & $6(2.60 \%)$ & $4(1.73 \%)$ & $6(2.60 \%)$ & $1(0.43 \%)$ \\
\hline$>6-8$ & $25(10.82 \%)$ & $2(0.86 \%)$ & $11(4.76 \%)$ & $6(2.60 \%)$ & 0 \\
\hline$>8-10$ & $35(15.15 \%)$ & $6(2.60 \%)$ & $5(2.16 \%)$ & 0 & $1(0.43 \%)$ \\
\hline$>10-12$ & $5(2.16 \%)$ & $2(0.86 \%)$ & $5(2.16 \%)$ & $6(2.60 \%)$ & $2(0.86 \%)$ \\
\hline
\end{tabular}

Table-III. Mechanism of injury with age

\section{DISCUSSION}

This study reveals that fall remains the most common mechanism of injury during pandemic lockdown holidays. The main factor in our study is noted to be kite flying which is one of the favorite home activity among children during spring vacations due to Basant Festival in our region. Spring/summer season is also studied with increased spikes in the pediatric trauma according to a recent 5 year retrospective review in south Florida.8 This supports the finding of falls among children more than 4 years of age but fall from bed or settees still counts to be the most common mechanism of injury among infants. This is further supported by ALSPAC (the Avon Longitudinal Study of Parents and Children, formerly the Avon Longitudinal Study of Pregnancy and Childhood) study conducted on 11466 infants with $53 \%$ of cases presenting with history of fall causing mild to moderate head injury. ${ }^{9}$

In previous studies conducted for holiday-related trauma, common mechanism of injury varies in distinct parts of the world in the milieu of different type of holidays. In the current situation Quartz India published an article on 9th April, 2020 stating that a lockdown, induced by the apocalyptic scenario of death and disease, is the exact opposite of a happy occasion. ${ }^{10} \mathrm{~A}$ study conducted in New south wales showed that Christmas and New year holidays are the busiest days for emergency departments but according to the study this increase (39\%) is mostly of GP type, not related to trauma. ${ }^{11}$ While there is an increased trend of Road side accidents in the countries which enjoy festive-holidays related to Ramadan and Eid. ${ }^{12-13}$

Another similar study done in king Abdul Aziz Hospital, Saudi Arabia published in 2017 showed that they had an average of 1.6 per day admissions in Pediatric emergency for trauma during holidays ${ }^{14}$ while our study shows a mean of 7.7 admissions which is a greater indicator of increased rate of pediatric trauma in our settings.

A recent study in South India discusses the fall as being the most common type of pediatric injury in decreasing frequency with age ${ }^{15}$ while Road side accidents increase in frequency with age. Our results were somewhat similar regarding road-side accidents but again this finding is not comparable with usual circumstances in the background of Covid-19 lock down. An article published in National newspaper "The News" on 
May 02, 2020 has clearly mentioned detailed data regarding reduction in the number of road side accidents of around $18-20 \%$ in Punjab and about $15-34 \%$ in whole Pakistan during the first four months of this year due to lockdown situation. ${ }^{16}$

Another study conducted in Greece showed, burn injuries are the most common injuries encountered during Easter holidays related to fireworks and homemade crackers. ${ }^{17}$ This totally contradicts our study where burn is related to hot liquids and electrocution. In contrast fireworks are prohibited for free sale due to governmental policies. A surveillance study by Pakistan National Emergency Department also showed that most of the burn cases are due to Scald burn around $64.3 \%$ as compared other modes of burn. ${ }^{18}$

Child sexual abuse has been on the rise in Pakistan for last five years. Recently a 6 month data is provided by a national newspaper shows the current rate of pediatric sexual abuse is 7 per day in Pakistan. ${ }^{19} \mathrm{~A}$ significant finding in our study dictates that there is not a single report of sexual abuse in children during this pandemic lockdown which strengthens the understanding of children supervision by parents.

The strengths of this study were its sufficiently large sample size during this lockdown period and it was a multicenter study primarily conducted in our region. No such study has been published on this topic to date. However there are few limitations to the study as data was collected from parents/guardians who were usually not present or busy during the accidents. So there is potential of the results regarding mechanism of injury to vary in cases of complex injuries like fall and burn, hit and stab etc. Moreover there is possibility of incomplete capturing of the situation from the far areas due to transport problems in lockdown situation. Further studies are required to elaborate the findings.

\section{CONCLUSION}

This study is first of its kind describing pediatric trauma in lockdown situation due to covid-19 pandemic. Most of the pediatric trauma was not severe. Road side accidents and child molestation were reduced due to direct parental supervision and refrain from unnecessary outdoor rambling of children in streets. We suggest to increase public awareness programs regarding home safety, parental supervision and strengthening of laws and regulations regarding home-inflicted injuries and resource allocation for the pediatric emergency personnel in the scenario where most of the medical attention is towards covid-19 related management.

Copyright@ 17 Aug, 2020.

\section{REFERENCES}

1. Alonge $O$, Khan UR, Hyder AA. Our shrinking globe: Implications for child unintentional injuries. Pediatr Clin North Am. 2016; 63(1):167-81.

2. Booth VM, Rowlands AV, Dollman J. Physical activity temporal trends among children and adolescents. J Sci Med Sport. 2015; 18(4):418-25.

3. COVID-19's devastating impact on children [Internet]. Human Rights Watch. 2020 [cited 30 April 2020]. Available from: https://www.hrw.org/news/2020/04/09/ covid-19s-devastating-impact-children.

4. COVID-19 is hurting children's mental health. Here's how to help [Internet]. World Economic Forum. 2020 [cited 2 May 2020]. Available from: https://www. weforum.org/agenda/2020/05/covid-19-is-hurtingchildrens-mental-health/.

5. Alhusain F, Alhassan N, Aljohi W, Alrumaih F, Al Jerian N, Alharthy N. Paediatric emergency department during the holidays: Findings from a 10-year analysis of visit rates and trauma patterns. Journal of Health Specialties. 2017; 5(3):142.

6. Kimia A, Lee L, Shannon M, Capraro A, Mays D, Johnston $P$ et al. Holiday ornament-related injuries in children. Pediatric Emergency Care. 2009; 25(12):819822.

7. Alnasser M, AISelaim N, Aldhukair S, Elbedah K, Tamim $\mathrm{H}$, Alazzam $\mathrm{S}$ et al. Patterns of pediatric trauma in Ramadan. Annals of Pediatric Surgery. 2012; 8(1):9-11.

8. Eyerly-Webb S, Solomon R, Young L, Bard K, Laituri $\mathrm{C}$, Rosenthal $\mathrm{A}$ et al. Impact of holidays on pediatric trauma admissions to a community hospital in south florida. Southern Medical Journal. 2019; 112(3):164169.

9. Warrington SA, Wright CM, Team AS. Accidents and resulting injuries in premobile infants: Data from the ALSPAC study. Archives of Disease in Childhood 2001; 85:104-107. 
10. Deshpande A. In locked down India, women fight coronavirus and domestic violence [Internet]. Quartz India. 2020 [cited 30 April 2020]. Available from: https:// qz.com/india/1838351/indias-coronavirus-lockdownleads-to-more-violence-against-women/.

11. Zheng W, Muscatello DJ, Chan AC. Deck the halls with rows of trolleys emergency departments are busiest over the Christmas holiday period. Med J Aust 2007; 187:630-3.

12. Tahir MN, Macassa G, Akbar AH, Naseer R, Zia A, Khan S. Road traffic crashes in Ramadan: An observational study. EMHJ. 2013; 19:s147-51.

13. Kumar R, Muzzammil M, Minhas MS, Bhatti A, Kumar V, Jahanzeb S. Road traffic accidents: Age and gender distribution and impact of religious month and holidays (Ramadan and Eid) on frequency of RTAs in Karachi Pakistan. Trauma International. 2016; 2(2):4043.

14. Othman A, Al-Nasser A, Mobaireek O, Alharthy N, AlMutairi M. Pattern of paediatric holiday-related injuries: An observational study from King Abdulaziz Medical City Trauma Registry [Internet]. Semanticscholar. org. 2018 [cited 20 April 2020]. Available from: https:// www.semanticscholar.org/paper/Pattern-Of-PaediatricHoliday-Related-Injuries-\%3A-An-Othman-Al-Nasser/ beaac4bf207db1dd7123c0f6c4043d117be87460.
15. Prabhakar Abhilash KP, Vincent D, George AS, Kalyaniwala K, Prajapathi A, Thomas SM. Pattern and outcome of unintentional pediatric trauma in the emergency department of a tertiary care hospital in South India. J Med Sci 2018; 38:269-74.

16. Death ratio of road accidents during lockdown in Punjab reduced by $15.34 \mathrm{pc}$ [Internet]. Thenews.com. pk. 2020 [cited 2 May 2020]. Available from: https:// www.thenews.com.pk/print/648513-death-ratio-of-roadaccidents-during-lockdown-in-punjab-reduced-by-15$34 \mathrm{pc}$.

17. Pallantzas A, Kourakos P, Stampolidis N, Papagianni E, Balagoura A, Stathopoulos A, et al. Burns during Easter festivities in Greece. Ann Burns Fire Disasters 2012; 25:171-7.

18. Siddiqui E, Zia N, Feroze A, Awan S, Ali A, Razzak J et al. Burn injury characteristics: Findings from Pakistan National emergency department surveillance study. BMC Emergency Medicine. 2015; 15(S2).

19. Child sexual abuse rate in Pakistan continues to be 7 children per day, Daily Times \{Internet\} 2019 Sep 20 [cited 2020 May 05] Available from: https://dailytimes. com.pk/469129/child-sexual-abuse-rate-in-pakistancontinues-to-be-7-children-per-day/.

\begin{tabular}{|c|l|l|l|}
\hline \multicolumn{3}{|c|}{ AUTHORSHIP AND CONTRIBUTION DECLARATION } \\
\hline Sr. \# & \multicolumn{1}{|c|}{ Author(s) Full Name } & \multicolumn{1}{|c|}{ Contribution to the paper } & Author(s) Signature \\
\hline 1 & Mahreen Zahra & $\begin{array}{l}\text { Conceived the data, Data } \\
\text { collection, manuscript writing. } \\
\text { Manuscript writing, Results } \\
\text { compilation. } \\
\text { Data collection, Data analysis, } \\
\text { Plagiarism check. } \\
\text { Data collection. }\end{array}$ \\
\hline 4 & Muhammad Kashif & Ikramullah Khan & Mateullah Majid
\end{tabular}

